Research Article

\title{
Energy and Fatigue Damage Evolution of Sandstone under Different Cyclic Loading Frequencies
}

\author{
Yidan Sun (iD) and Yu Yang (D) $^{2}$ \\ ${ }^{1}$ School of Civil and Ocean Engineering, Jiangsu Ocean University, Lianyungang 222000, China \\ ${ }^{2}$ School of Civil Engineering, Liaoning Technical University, Fuxin 123000, China \\ Correspondence should be addressed to Yu Yang; yangyu9300@163.com
}

Received 6 February 2021; Revised 18 April 2021; Accepted 24 May 2021; Published 7 June 2021

Academic Editor: Pengfei Wang

Copyright () 2021 Yidan Sun and Yu Yang. This is an open access article distributed under the Creative Commons Attribution License, which permits unrestricted use, distribution, and reproduction in any medium, provided the original work is properly cited.

\begin{abstract}
To study the energy dissipation characteristics and damage evolution law of sandstone under cyclic loading, uniaxial cyclic loading tests are conducted on sandstone specimens under different frequencies with an MTS-815 rock testing machine. Furthermore, the characteristics of elastic modulus and energy evolution law during cyclic loading and unloading are explored. The results show that the loading and unloading moduli increase with the loading frequency. Under higher frequencies, the deformation resistance of the specimen is stronger, the elastic energy stored in a single cycle of loading is larger, the released energy is less, and it is less likely for the specimen to be damaged. At the beginning of loading, the energy dissipation ratio $K$ decreases slowly with increasing loading cycles, and it then remains stable. When the specimen is close to failure, an inflection point of $K$ appears, and $K$ increases rapidly. Furthermore, the evolution equation of the damage variable is derived according to the strength characteristics and energy evolution law in the process of cyclic loading, and the reasons for the failure of sandstone specimens are explained from the perspectives of energy and fatigue damage.
\end{abstract}

\section{Introduction}

The essence of rock failure is instability caused by the constant exchange of energy with the external environment $[1,2]$. Underground rock mass accumulates and dissipates energy repeatedly under the action of the dynamic load produced by blasting or excavation [3-7], which is equivalent to subjecting the surrounding rock to fatigue (cyclic) loading, leading to instability of rock mass. Therefore, the study of rock energy transformation under cyclic load is of great significance to analyze the stability of underground engineering.

An indoor test is an effective method to quantitatively measure rock deformation and failure. Researchers carried out uniaxial and triaxial cyclic loading and unloading tests on rock salt, sandstone, and marble under different confining pressures, stress amplitudes, and cyclic loading frequencies, respectively, to study the deformation law, strength characteristics, fatigue characteristics, damage evolution law, and damage accumulation model of rock [8-10]. In recent years, some scholars [11-15] studied the behavior of energy dissipation and release in the process of rock deformation and failure under uniaxial compression and revealed the evolution of volume energy, elastic energy, and dissipated energy during rock mass failure; subsequently, they obtained the characteristics of energy accumulation and dissipation before and after the peak compressive force. In addition, some scholars [16-19] studied the evolution of damping coefficient, elastic modulus, and dissipated energy under different confining pressures, loading frequencies, and loading amplitudes through uniaxial or triaxial cyclic loading and unloading tests, and they established the constitutive equation of the stress-strain evolution curve. In the aforementioned research, there is a basic consensus on the energy conversion under external load; that is, the work done by the external load on the rock gradually turns into elastic energy and dissipates energy during the loading process, causing the failure of the rock specimen. When rock failure occurs, the elastic energy decreases, and the dissipated energy increases rapidly. 
The deformation and failure process of rock material under external load is also a process of damage accumulation. Studying the damage evolution law of rock material from the perspective of energy dissipation can reveal the damage evolution law of rock in essence. Zhang et al. [20], Yang et al. [21], and $\mathrm{Xu}$ et al. [22] defined the damage variable in terms of energy dissipation, studied the damage evolution law of granite and mudstone under different confining pressures and load levels, and predicted the fatigue damage life of mudstone.

In the above studies of rock material damage under cyclic loading from the perspective of energy dissipation, the number of cycles considered is less and the initial cyclic stress mostly started from $0 \mathrm{MPa}$ in the cyclic loading experiment. In addition, some studies used graded loading to analyze fatigue damage, which causes energy dissipation to a certain extent, and the accuracy of the results was poor. Further, the above research results defined fatigue damage variables from the perspective of energy dissipation and elastic modulus separately and not the combination of both. The change in elastic modulus reflects the damage process of the internal microstructure of rock and represents the changing trend of the stress-strain curve. Energy in the loading process of rock is a parameter obtained from the stress-strain curve trend and can be used to characterize the internal state change of rock. To a certain extent, it reflects the deformation state of rock during cyclic loading and unloading and reveals the deformation and failure evolution of rock under cyclic loading. Therefore, the combination of elastic modulus and energy can reveal the damage evolution characteristics of rock in essence. In this study, cyclic loading tests of sandstone under different loading frequencies are conducted to determine the fatigue characteristics and energy evolution law of rock. The fatigue damage evolution equation of sandstone is established by combining elastic modulus and energy; this equation is of great significance to determine the stability of underground engineering.

\section{Materials and Methods}

2.1. Specimen and Equipment. The sandstone specimens were extracted from the roadway roof at a buried depth of $1000 \mathrm{~m}$ in the West Second mining area of Hongyang No. 3 Mine, Liaoyang City, Liaoning Province, China. In compliance with the test procedures listed by the International Society of Rock Mechanics [23], the shape of all tested sandstone specimens is cylindrical with approximately $50 \mathrm{~mm}$ diameter and $100 \mathrm{~mm}$ length. To ensure the consistency of physical and mechanical properties of the specimens, specimens with rough, uneven, or defective surfaces were not used. The diameter, perimeter, weight, and other parameters of the specimens were measured, and the density of each specimen was calculated. The specimens were divided into four groups, each consisting of three specimens. The grouping number and physical parameters are shown in Table 1. An MTS-815 electrohydraulic servo rock test system was adopted for the cyclic loading test (Figure 1).
2.2. Test Method. The existing research results show that $[24,25]$ there is a critical value for the fatigue failure of rock under cyclic loading, which generally takes the yield stress as the reference, and the fatigue failure of rock is affected by the upper limit of cyclic loading stress. Therefore, uniaxial compression tests were performed on group 1 to obtain the uniaxial compressive strength of the specimens, which is used as the basis for selecting the reasonable upper limit value of stress $\sigma_{\max }$. The fatigue damage tests were conducted on groups 2-4 with loading frequencies of $0.5,1.0$, and $2.0 \mathrm{~Hz}$, respectively; the mechanical properties of rock under different loading frequencies were studied by keeping the stress amplitude constant. The loading curves for groups 2-4 of specimens are divided into two stages: linear loading and cyclic loading. During the test, the specimens were loaded axially to a certain value, $\sigma_{\max }$, and then cyclically loaded. The loading process is shown in Figure 2; here, $\sigma_{\max }$ and $\sigma_{\min }$ are the upper and lower limits of each cyclic loading and $T$ is the cyclic loading period. The stress-velocity control method was adopted in the test. After loading each specimen to the upper limit of cyclic loading at a rate of $0.2 \mathrm{MPa} / \mathrm{s}$ under axial compression, each specimen was subjected to 2000 cycles of loading.

2.3. Calculation Principle and Method. The stress-strain law of natural rock during loading and unloading shows that the strain decreases with decreasing stress during unloading. However, due to residual deformation, the unloading curve generally does not return along the path of the loading curve, and the phenomenon of strain lag stress occurs. The loading and unloading curves form an approximately closed hysteresis loop, and a series of hysteresis loops form the hysteresis curve [25]. Figure 3 shows the hysteresis loop under a single cycle of the cyclic loading test. The slopes of the loading and unloading curves on the hysteresis loop represent the loading modulus $\left(E_{l i}\right)$ and the unloading modulus $\left(E_{u i}\right)$, respectively. The secant method was used to calculate the loading and unloading moduli:

$$
\begin{gathered}
E_{l i}=\frac{\sigma_{\max }-\sigma_{\min }}{\varepsilon_{m i}-\varepsilon_{l i}}, \\
E_{u i}=\frac{\sigma_{\max }-\sigma_{\min }}{\varepsilon_{m i}-\varepsilon_{u i}} .
\end{gathered}
$$

Here, $\sigma_{\max }$ and $\sigma_{\min }$ are the upper limit and lower limit of stress, respectively, $\mathrm{MPa} ; \varepsilon_{m i}$ is the maximum strain of a cycle; $\varepsilon_{l i}$ and $\varepsilon_{u i}$ are the strains at the beginning and end of a cycle, respectively.

According to the first law of thermodynamics, the total energy $U$ produced by the external load on the rock is equal to the sum of the elastic energy $U^{e}$ and the dissipated energy $U^{d}$; that is [18],

$$
U=U^{\mathrm{e}}+U^{\mathrm{d}}
$$

The relationship between elastic energy $U_{i}^{e}$ and dissipated energy density $U_{i}^{d}$ per unit volume of rock mass under loading and unloading conditions is shown in Figure 3. For the cyclic loading stress-strain curve, when the stress is 
TABle 1: Parameters for different rocks tested.

\begin{tabular}{cccccccc}
\hline Groups & Specimen & $D(\mathrm{~mm})$ & $L(\mathrm{~mm})$ & $\mathrm{M}(\mathrm{G})$ & $\rho\left(\mathrm{g} \cdot \mathrm{cm}^{-3}\right)$ & Average density $\left(\mathrm{g} \cdot \mathrm{cm}^{-3}\right)$ & Loading mode \\
\hline \multirow{3}{*}{1} & U1 & 50.10 & 99.84 & 520.3 & 2.645 & 2.630 & Uniaxial compression \\
& U2 & 49.42 & 100.02 & 502.1 & 2.618 & Uniaxial compression \\
& U3 & 48.82 & 99.78 & 490.4 & 2.627 & Uniaxial compression \\
2 & CF1-1 & 49.02 & 100.3 & 499.8 & 2.6403 & Cyclic loading \\
& CF1-2 & 50.04 & 100.9 & 512.3 & 2.5817 & Cyclic loading \\
& CF1-3 & 48.96 & 99.5 & 495.7 & 2.6462 & Cyclic loading \\
3 & CF2-1 & 48.24 & 99.9 & 474.9 & 2.6010 & Cyclic loading \\
& CF2-2 & 49.64 & 100.12 & 510.6 & 2.6352 & Cyclic loading \\
& CF2-3 & 49.18 & 99.86 & 495.9 & 2.6142 & Cyclic loading \\
4 & CF3-1 & 48.44 & 100.2 & 487.2 & 2.6384 & Cyclic loading \\
& CF3-2 & 49.96 & 99.84 & 513.8 & 2.6252 & Cyclic loading \\
& CF3-3 & 49.12 & 99.54 & 499.6 & 2.6486 & 2.6374 & Cyclic loading \\
\hline
\end{tabular}

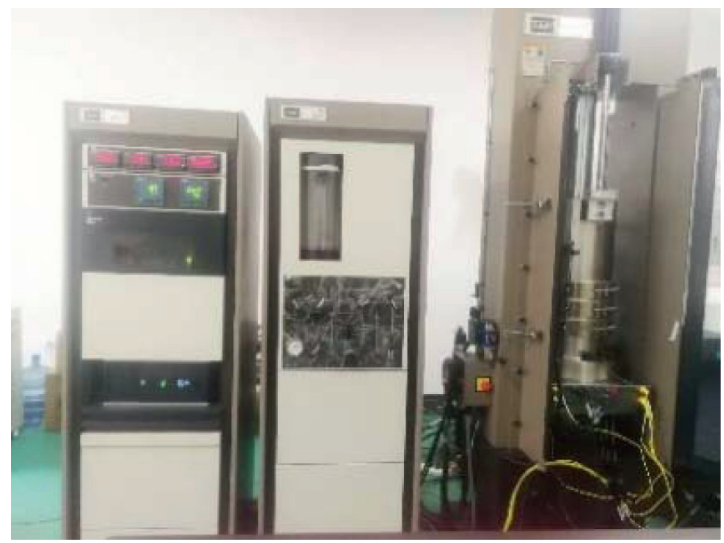

(a)

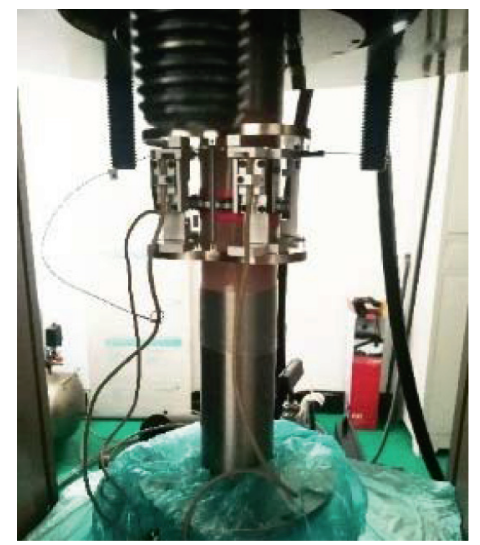

(b)

Figure 1: MTS-815 pressure test system.

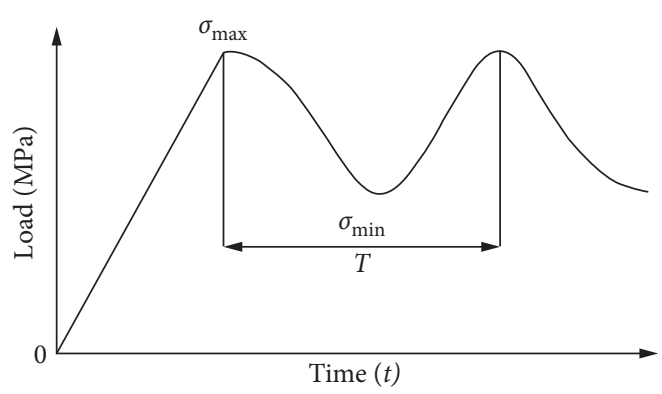

FIgURE 2: Schematic diagram of cyclic loading.

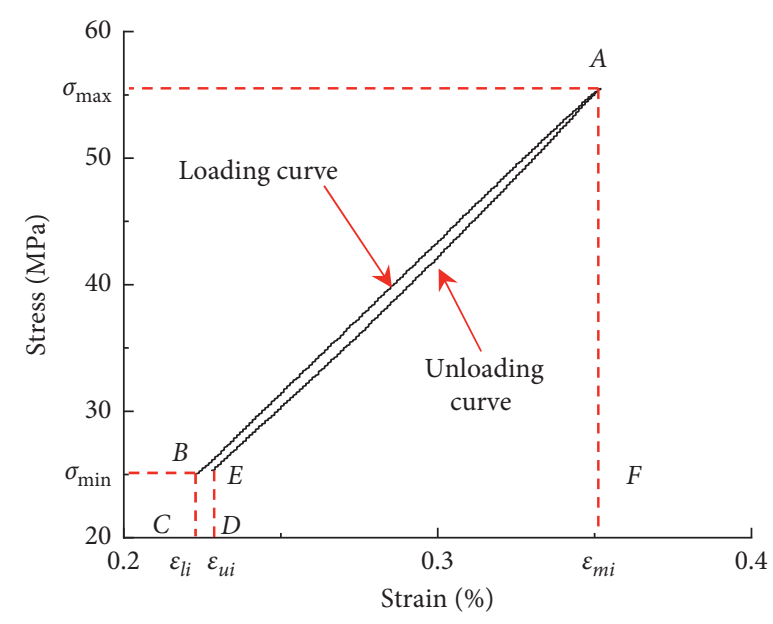

Figure 3: Single-cycle loading and unloading hysteresis loop. 
loaded from $\sigma_{\min }$ to $\sigma_{\max }$, the released elastic energy density $U_{i}^{e}$ is the area between the unloading curve and the strain axis, which can be approximately expressed as the area of graph AEDF. The total energy density $U_{i}$ is the area between the loading curve and the strain axis, which can be approximately expressed as the area of graph $\mathrm{ABCF}$. The zone between the loading and unloading stress-strain curves represents the dissipated energy density $U_{i}^{d}$, which causes irreversible plastic deformation and internal damage. Based on the proposed method of rock energy determination, the equations for related energy densities are expressed as follows:

$$
\begin{aligned}
& U_{i}=\int_{\varepsilon_{l i}}^{\varepsilon_{m i}} \sigma d \varepsilon \approx \frac{\left(\sigma_{\max }+\sigma_{\min }\right)}{2}\left(\varepsilon_{m i}-\varepsilon_{l i}\right), \\
& U_{i}^{e}=\int_{\varepsilon_{u i}}^{\varepsilon_{\mathrm{mi}}} \sigma d \varepsilon \approx \frac{\left(\sigma_{\max }+\sigma_{\min }\right)}{2}\left(\varepsilon_{m i}-\varepsilon_{u i}\right), \\
& U_{i}^{d}=U-U_{e} \approx \frac{\left(\sigma_{\max }+\sigma_{\min }\right)}{2}\left(\varepsilon_{u i}-\varepsilon_{l i}\right),
\end{aligned}
$$

where $\varepsilon_{m i}$ is the corresponding strain to $\sigma_{\max }$.

Combined with equation (1), the total energy density $U_{i}$ and elastic energy density $U_{i}^{e}$ in a single cycle of the loading and unloading process can be rewritten as

$$
\begin{aligned}
& U^{i}=\frac{\sigma_{\max }^{2}-\sigma_{\min }^{2}}{2 E_{l i}}, \\
& U_{i}^{e}=\frac{\sigma_{\max }^{2}-\sigma_{\min }^{2}}{2 E_{u i}} .
\end{aligned}
$$

\section{Results and Discussion}

3.1. Uniaxial Compression Test Results. Group 1 specimens were subjected to uniaxial compression tests to obtain the uniaxial compressive strength of sandstone specimens in order to determine a reasonable upper limit $\sigma_{\max }$. The results of the uniaxial compression test are shown in Table 2 and Figure 4.

According to Table 2 and Figure 4, the uniaxial compressive strength of sandstone is $60.5 \mathrm{MPa}$, the yield strength is $50 \mathrm{MPa}$, and the upper limit stress value $\sigma_{\max }$ of cyclic loading is determined to be $45 \mathrm{MPa}$. The lower limit stress value $\sigma_{\min }$ is determined as $25 \mathrm{MPa}$ by referring to the overburden stress on 12\# coal roof strata. The specific test process is shown in Table 1.

3.2. Cyclic Loading Test Results. According to the test results given in Table 3, group 2 specimens were subjected to cyclic loading under a frequency of $0.5 \mathrm{~Hz}$; specimens CF1-1, CF12 , and CF1-3 were destroyed after 869,821 , and 897 cycles, respectively. Under loading frequencies of $1.0 \mathrm{~Hz}$ and $2 \mathrm{~Hz}$, the specimens were not damaged after 2000 cycles. Because the damage evolution law of specimens in the same group is similar, we selected the test results of specimens CF1-1, CF21 , and CF3-1 to study the fatigue damage characteristics of sandstone under different loading frequencies.

\subsection{Fatigue Characteristics of Sandstone under Cyclic Loading}

3.3.1. Characteristics of the Stress-Strain Curve. From the stress and strain data of CF1-1, CF2-1, and CF3-1 in cyclic loading tests, we obtained the axial stress-strain curves (Figure 5) and the hysteresis curves at different stages under $0.5 \mathrm{~Hz}$ loading frequency (Figure 6). Under loading frequencies of $1 \mathrm{~Hz}$ and $2 \mathrm{~Hz}, \mathrm{CF} 2-1$ and CF3-1 were not damaged after 2000 cycles. Under a loading frequency of $0.5 \mathrm{~Hz}, \mathrm{CF} 1-1$ experienced fatigue failure after 869 cycles. The test results show that the deformation and failure of sandstone under cyclic loading are affected by not only the maximum stress but also the loading frequency.

The stress-strain curve of the sandstone specimen at a loading frequency of $0.5 \mathrm{~Hz}$ can be divided into three stages: the first stage is compaction stage; this stage is the transition stage from linear loading to cyclic loading, and the hysteresis curve is sparse in this stage. Based on Figure 5, the area of the first hysteresis loop is larger than that of the later hysteresis loop, which indicates that more energy is consumed in this stage. The second stage is stable loading stage; in this stage, the deformation of the sandstone specimen is relatively stable, the hysteresis curves are dense, and the energy consumed in each cycle is less than that in the previous stage. The third stage is accelerated failure stage; in this stage, the hysteresis curve is loose, and the area of the single hysteresis loop and the plastic deformation increase rapidly with the number of cycles. Fatigue failure of the sandstone specimen occurs when the plastic deformation reaches the limit.

3.3.2. Strength Characteristics. The strength characteristics of sandstone specimens are characterized by loading and unloading moduli. According to equation (1), the variation of loading and unloading moduli with the number of cycles at different frequencies is plotted in Figure 7.

From a macro perspective, the elastic modulus is a measure of an object's ability to resist elastic deformation. Figure 7 indicates that the loading and unloading moduli increase with the loading frequency, suggesting that the greater the loading frequency is, the stronger the deformation resistance of the specimen is, and the more difficult the specimen is to be damaged. The unloading modulus is slightly larger than the loading modulus, which is due to the plastic deformation of sandstone material during unloading.

In general, under loading frequencies of $1 \mathrm{~Hz}$ and $2 \mathrm{~Hz}$, the loading and unloading moduli initially decrease and finally become stable as the number of cycles increases. Under a loading frequency of $0.5 \mathrm{~Hz}$, with increasing number of cycles, the loading modulus decreases and the unloading modulus first decreases and then becomes stable and finally increases rapidly.

Under a loading frequency of $0.5 \mathrm{~Hz}$, both moduli change in three stages: in the compaction stage, the loading and unloading moduli decrease with increasing number of cycles. Owing to the existence of small cracks, holes, and weak interlayers in natural rocks, these parts are prone to deformation and failure in the initial stage of cyclic loading. Therefore, the loading and unloading moduli are large in the 
TABLE 2: Uniaxial compression test results.

\begin{tabular}{|c|c|c|c|c|c|}
\hline Specimen & Uniaxial compressive strength (MPa) & Average $(\mathrm{MPa})$ & Yield strength $(\mathrm{MPa})$ & Elastic modulus (GPa) & Poisson's ratio \\
\hline $\mathrm{U} 1$ & 61.2 & & & & \\
\hline $\mathrm{U} 2$ & 60.5 & 60.9 & 50 & 14.8 & 0.21 \\
\hline U3 & 59.4 & & & & \\
\hline
\end{tabular}

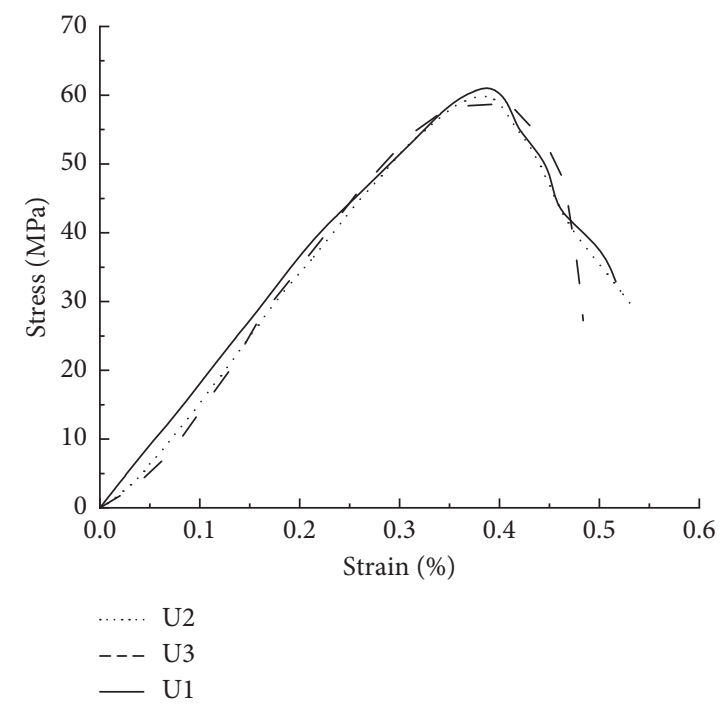

FIgURE 4: Stress-strain curve of uniaxial compression test.

TABle 3: Cyclic loading test results.

\begin{tabular}{lccccc}
\hline Specimen & $\sigma_{\max }(\mathrm{MPa})$ & $\sigma_{\min }(\mathrm{MPa})$ & $f(\mathrm{~Hz})$ & Failure strength $(\mathrm{MPa})$ & Cycle number \\
\hline CF1-1 & 45 & 25 & & 45 & 45 \\
CF1-2 & 45 & 25 & 0.5 & 45 & 821 \\
CF1-3 & 45 & 25 & & - & 897 \\
CF2-1 & 45 & 25 & 1.0 & - & 2000 \\
CF2-2 & 45 & 25 & & - & 2000 \\
CF2-3 & 45 & 25 & 2.0 & - & 2000 \\
CF3-1 & 45 & 25 & & - & 2000 \\
CF3-2 & 45 & 25 & & & 2000 \\
CF3-3 & 45 & 25 & & & \\
\hline
\end{tabular}

early stage of loading. As the internal defects are gradually compacted, the deformation rate decreases and the loading and unloading moduli decrease gradually. In the stable loading stage, the loading and unloading moduli tend to be stable, the deformation is stable, and the plastic deformation accumulation is slow. In the accelerated failure stage, the loading modulus decreases rapidly and the unloading modulus increases rapidly. The fatigue failure of the specimen occurs when the plastic deformation accumulates to a certain extent.

3.3.3. Energy Dissipation Characteristics. The energy evolution characteristics of rock specimens during cyclic loading and unloading are expressed by the variation laws of total energy density, elastic energy density, and dissipated energy density. The elastic energy density and dissipated energy density are obtained according to equation (3).
Figure 8 shows the variation of elastic energy density and dissipated energy density during cyclic loading under different loading frequencies. With increasing loading frequency, the elastic energy density increases and the dissipated energy density decreases. The reason is that when the loading frequency increases, the damage propagation and energy dissipation of rock are limited to a certain extent and more energy is stored in the rock, which is equivalent to improving the antideformation ability of the rock. At the same frequency, the trend of change in elastic energy density and dissipative energy density is the opposite. Under loading frequencies of $1.0 \mathrm{~Hz}$ and $2.0 \mathrm{~Hz}$, the specimens were not damaged and the energy evolution curves are similar. With increasing number of cycles, the elastic energy density first increases rapidly and then remains stable, while the dissipated energy density first decreases rapidly and then remains stable. Under a loading frequency of 0.5 , in the initial stage of cyclic loading, the difference between the elastic energy density and the dissipated energy density increases gradually, the defects in the 


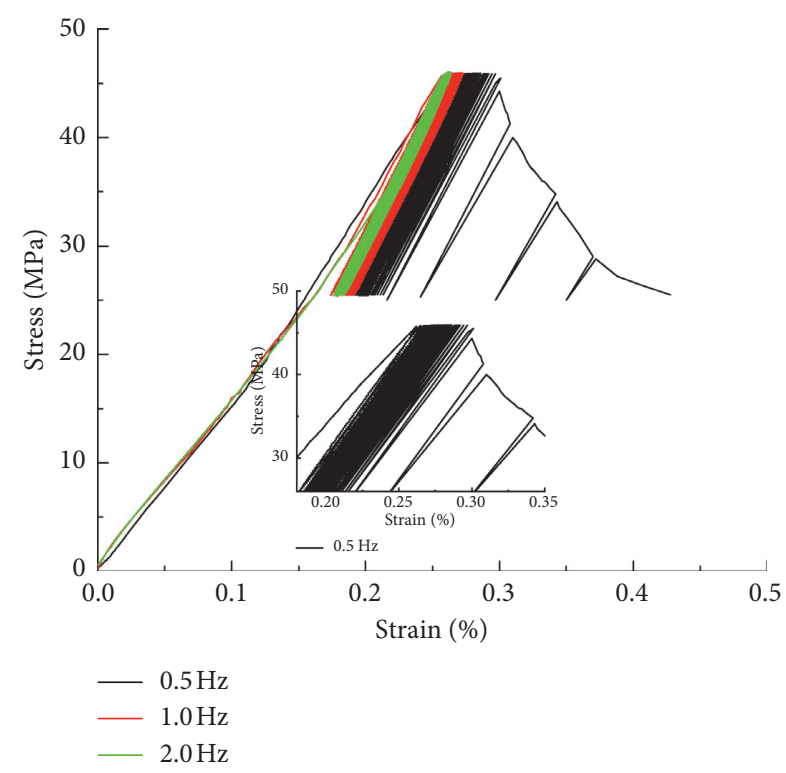

FIGURe 5: Axial stress-strain curves under cyclic loading at different frequencies.

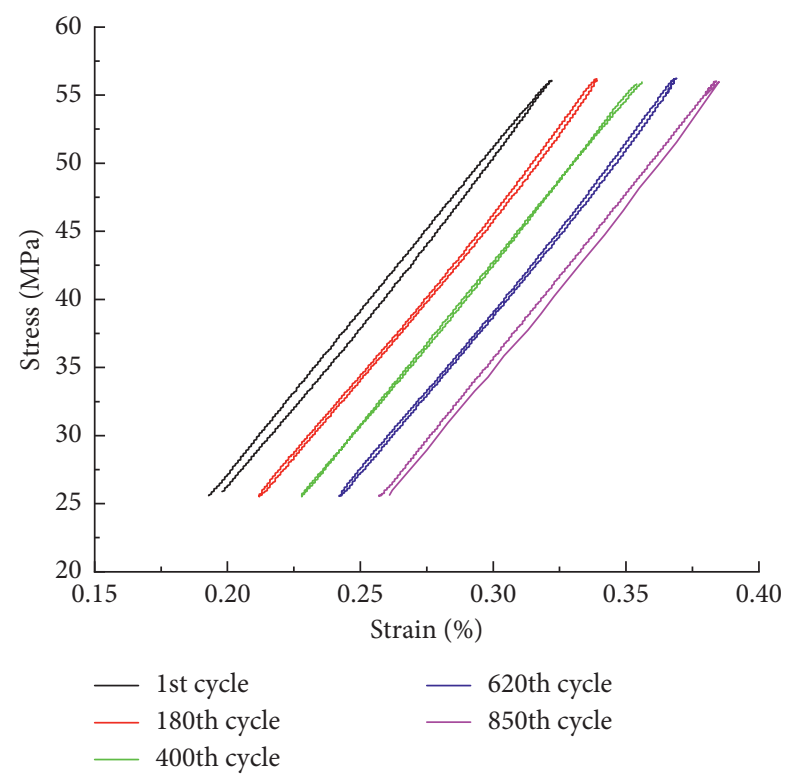

Figure 6: Hysteresis curves at different stages under a loading frequency of $0.5 \mathrm{~Hz}$.

rock are gradually compacted, and the work done by the external force is mainly transformed into elastic energy. Subsequently, both energy densities enter the stable stage with increasing number of cycles, and the energy absorbed and dissipated in a single loading and unloading cycle remains unchanged. When the specimen is close to failure, the elastic energy density suddenly releases and decreases rapidly, and the dissipated energy density increases sharply. Therefore, the energy variation of rock failure is characterized by energy release and dissipation. Under this loading frequency, two inflection points appear in the elastic energy density and dissipated energy density curves, and the elastic energy density evolves in the pattern of "increase-stable-decrease," while the dissipated energy density follows the reverse pattern.

Figure 9 shows the evolution of total energy density during cyclic loading. The figure indicates that it is similar to the evolution of elastic energy density, because the total energy is mainly transformed into elastic performance in the whole process.

Most natural rocks belong to elastic-plastic anisotropic materials, and cracks and holes are formed in them. When work is done by an external force, part of the energy is converted into elastic energy and accumulated in the rock, while the other part is consumed in the process of crack or hole initiation, expansion, and penetration. This consumed energy is called dissipated energy. When the dissipated energy accumulates to a certain extent, the rock will be destroyed. Therefore, energy storage and dissipation during the rock loading process can be defined by the energy dissipation ratio $K$ [2], which can be used as the basis for determining rock strength failure.

$$
K=\frac{U_{d}}{U_{e}}
$$

The curves of the energy dissipation ratio $K$ of the sandstone specimens under different loading frequencies are shown in Figure 10 . The energy dissipation ratio $K$ decreases rapidly with the number of cycles and then remains stable under loading frequencies of $1 \mathrm{~Hz}$ and $2 \mathrm{~Hz}$. When the loading frequency is $0.5 \mathrm{~Hz}$, the evolution law of energy dissipation ratio $K$ in the first two stages is similar to that under $1 \mathrm{~Hz}$ and $2 \mathrm{~Hz}$ loading frequencies. After the stable stage, a new inflection point appears in the curve and $K$ rapidly increases; then, the sandstone specimen is damaged. Combined with the energy dissipation characteristics of sandstone in the process of cyclic loading, the energy behavior of rock failure is mainly manifested in the rapid release of elastic energy and consumption of a large amount of energy, which is directly manifested in the sudden increase of the energy dissipation ratio $K$.

The strength state of rock under external force is closely related to energy evolution. When the loading frequency is lower than a certain threshold, the internal fracture of rock occurs after several cycles, a large amount of elastic energy ( $U^{e}$ decreases) is released along the fracture surface, and a large amount of energy ( $U^{d}$ increases) is consumed. The energy dissipation ratio $K$ increases, and an inflection point appears in the curve. The sudden change in $K$ represents rock failure and strength failure.

3.4. Damage Evolution. Considering the change in the loading and unloading moduli during cyclic loading, assuming that the rock is damaged in different degrees during each cycle of loading and unloading, the loading and unloading moduli are defined as [19]

$$
\begin{aligned}
E_{l i(D)} & =E_{l i} \cdot(1-D), \\
E_{u i(D)} & =E_{u i} \cdot(1-D),
\end{aligned}
$$

where $D$ is the damage variable and $E_{l i(D)}$ and $E_{u i(D)}$ are the loading and unloading moduli after damage during each cycle of loading and unloading. 


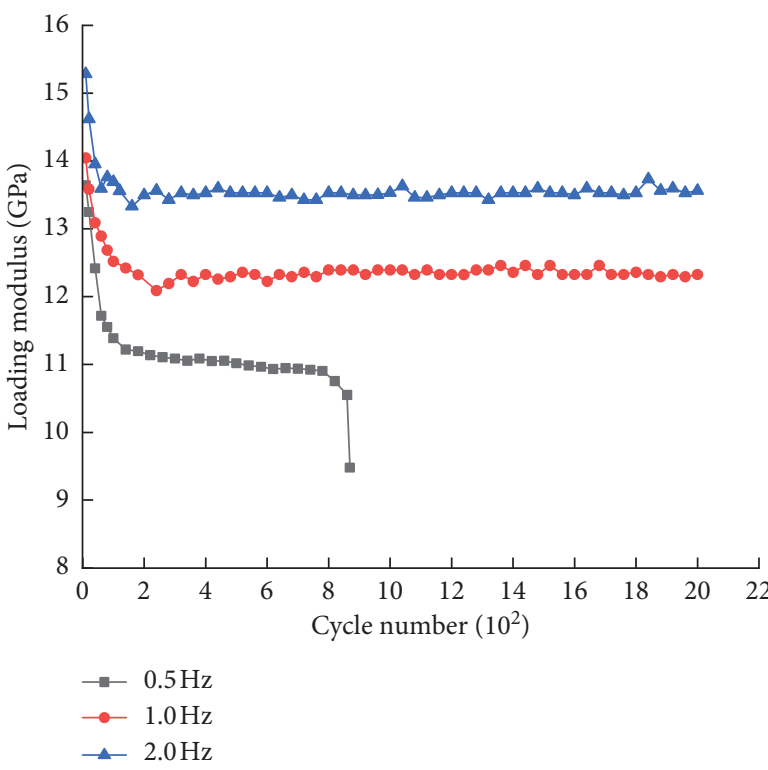

(a)

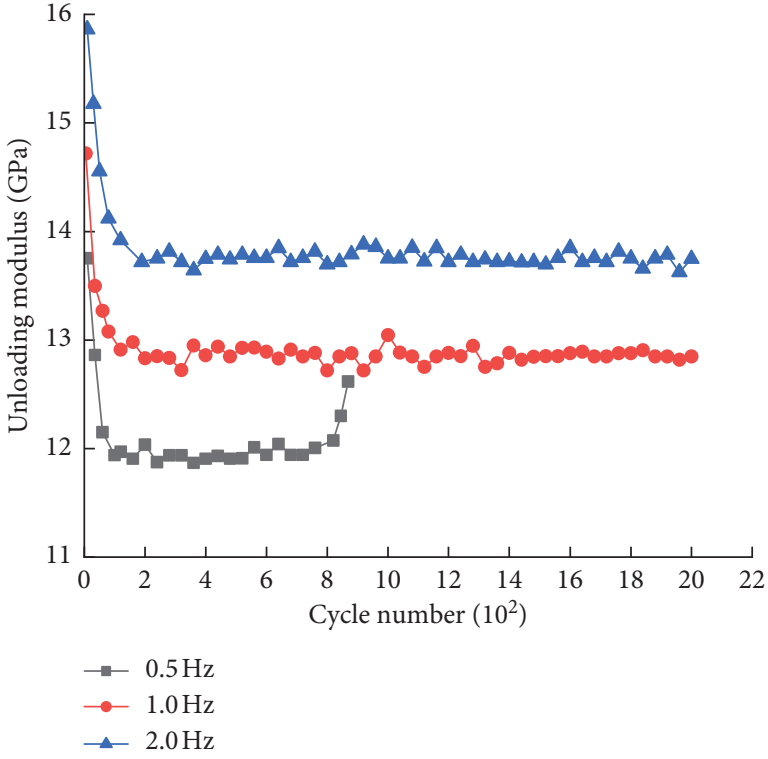

(b)

Figure 7: Variation of loading and unloading moduli of sandstone specimens under loading cycles with different frequencies. (a) Loading modulus. (b) Unloading modulus.

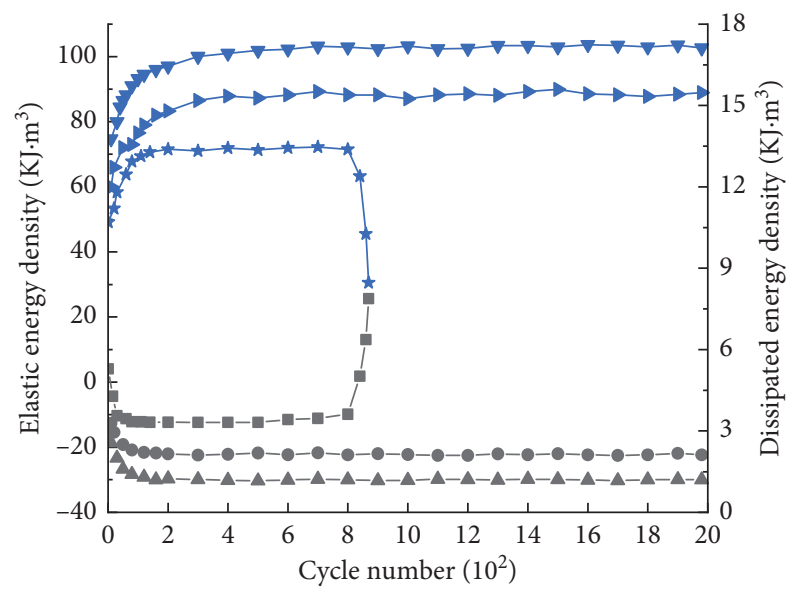

$\begin{array}{ll}\text { Elastic energy density } & \text { Dissipated energy density } \\ \rightarrow-2.0 \mathrm{~Hz} & -\triangle-2.0 \mathrm{~Hz} \\ \rightarrow-1.0 \mathrm{~Hz} & --1.0 \mathrm{~Hz} \\ \star-0.5 \mathrm{~Hz} & --0.5 \mathrm{~Hz}\end{array}$

FIGURE 8: Evolution curves of elastic energy density and dissipation energy density under different loading frequencies.

Equation (4) is then rewritten as follows:

$$
\begin{gathered}
U_{i}=\frac{\sigma_{\max }^{2}-\sigma_{\min }^{2}}{2 E_{l i(D)}}=\frac{\sigma_{\max }^{2}-\sigma_{\min }^{2}}{2 E_{l i} \cdot(1-D)}, \\
U_{i}^{e}=\frac{\sigma_{\max }^{2}-\sigma_{\min }^{2}}{2 E_{u i(D)}}=\frac{\sigma_{\max }^{2}-\sigma_{\min }^{2}}{2 E_{u i} \cdot(1-D)} .
\end{gathered}
$$

Combining equations (2) and (7), the functional relationship of damage variables, dissipated energy density,

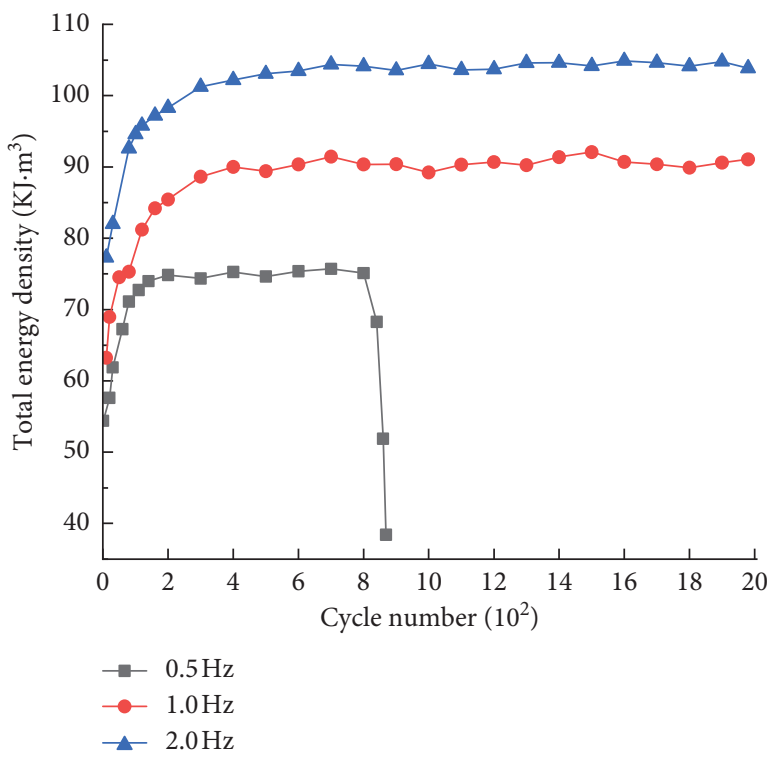

Figure 9: Total energy density evolution curve under different loading frequencies.

loading modulus, and unloading modulus during cyclic loading is obtained as follows:

$$
D=1-\frac{\sigma_{\max }^{2}-\sigma_{\min }^{2}}{2 U_{i}^{d}}\left(\frac{1}{E_{l i}}-\frac{1}{E_{u i}}\right) .
$$

The dissipated energy density, loading modulus, and unloading modulus are substituted into equation (8), since they all change with the number of cycles, and the curves of the damage variable $D$ with the number of cycles at different frequencies are obtained as shown in Figure 11. 


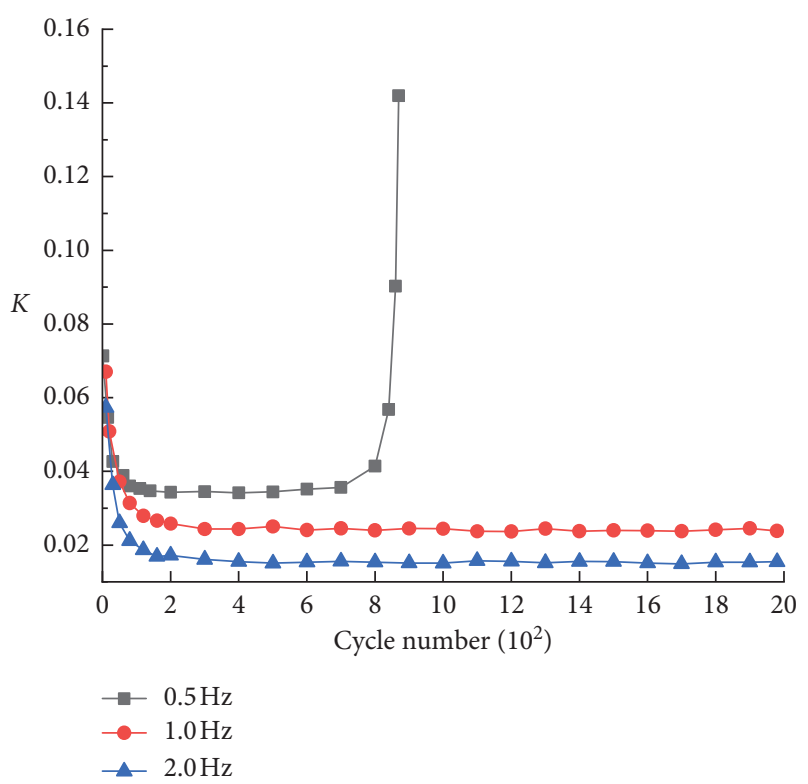

FIgURE 10: Curve of energy dissipation ratio under different loading frequencies.

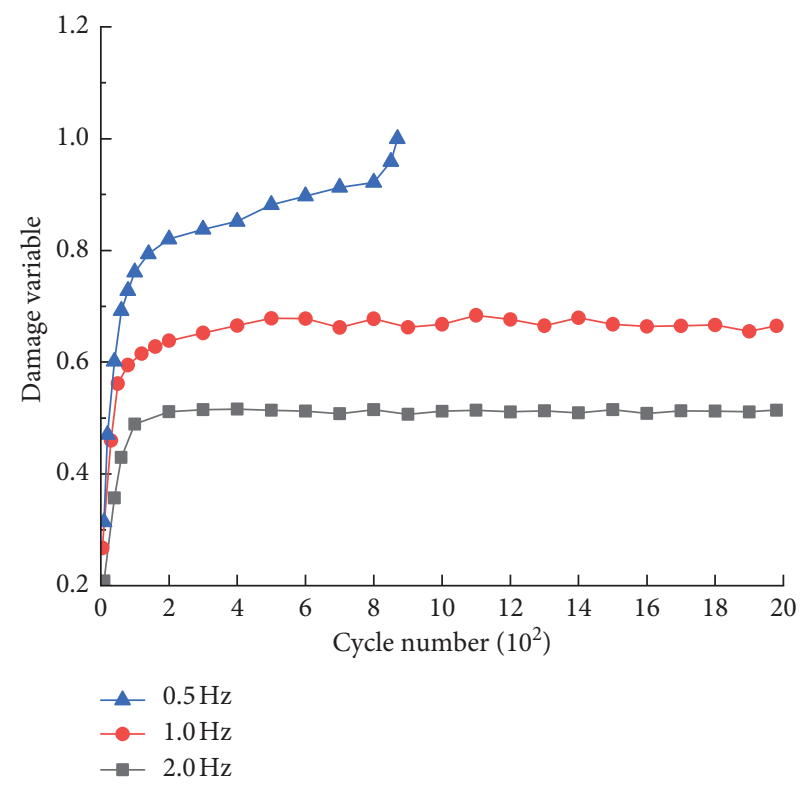

Figure 11: Change curve of the damage variable under different loading frequencies.

The figure shows that, under loading frequencies of $1.0 \mathrm{~Hz}$ and $2.0 \mathrm{~Hz}$, the damage variable initially increases rapidly and then remains unchanged with the number of cycles; this is the reason for no failure of sandstone specimens under these loading frequencies. Under a loading frequency of $0.5 \mathrm{~Hz}$, the damage variable changes rapidly with increasing number of cycles, with a continuous increase during cyclic loading. When the specimen is close to failure, the damage variable increases rapidly; this is the precursor of rock failure.

\section{Conclusion}

(1) The deformation and failure of sandstone under cyclic loading are affected by not only the maximum stress but also the loading frequency. The loading and unloading moduli increase with the loading frequency. As the loading frequency increases, the damage propagation and energy dissipation of the rock are limited to a certain extent, which has enhanced antideformation ability and the rock specimen is less likely to be damaged.

(2) The energy evolutions were similar in the initial and stable cyclic loading stages under different loading frequencies. The elastic energy and dissipated energy showed opposite trends under the same loading frequency. Under a loading frequency of $0.5 \mathrm{~Hz}$, the curves of elastic energy density and dissipated energy density consisted of two inflection points, and the evolution of elastic energy density followed the pattern of "increase-stable-decrease," while that of dissipated energy density was the opposite.

(3) As the loading frequency decreased, the energy dissipation ratio $K$ increased gradually; when the sandstone specimen was close to failure, there was an inflection point in the curve of energy dissipation ratio $K$, and the $K$ value increased rapidly. The sudden increase in $K$ is considered the criterion of rock failure and strength failure in the process of cyclic loading.

(4) According to the strength characteristics and energy evolution law of the specimen in the cyclic loading process, the equation of the rock damage variable $(D)$ evolution was deduced, and the damage evolution characteristics under different cyclic loading frequencies were determined. Subsequently, the reasons for the instability and failure of sandstone specimens under cyclic loading were explained.

\section{Data Availability}

The data used to support the findings of this study are available from the corresponding author upon request.

\section{Conflicts of Interest}

The authors declare that they have no conflicts of interest.

\section{Authors' Contributions}

The first draft of the manuscript was written by Yidan Sun. Both authors contributed to the study conception and design, carried out material preparation, data collection, and analysis, and read and approved the final manuscript.

\section{Acknowledgments}

The authors gratefully acknowledge the National Key Research and Development Program of China (Grant no. 2018YFC0604705), the National Natural Science Foundation 
of China (Grant no. 51774167), and Science and Technology Innovation Leading Talent Project of Liaoning Province (Grant no. XLYC1802063) for supporting this work.

\section{References}

[1] H. P. Xie, Y. Ju, and L. Y. Li, "Criteria for strength and structural failure of rocks based on energy dissipation and energy release principles," Chinese Journal of Rock Mechanics and Engineering, vol. 24, no. 17, pp. 3003-3010, 2005.

[2] Z. Y. Li, G. Wu, T. Z. Huang, and Y. Liu, "Variation of energy and criteria for strength failure of shale under traixial cyclic loading," Chinese Journal of Rock Mechanics and Engineering, vol. 37, no. 3, pp. 662-670, 2018.

[3] E. Liu, R. Huang, and S. He, "Effects of frequency on the dynamic properties of intact rock samples subjected to cyclic loading under confining pressure conditions," Rock Mechanics and Rock Engineering, vol. 45, no. 1, pp. 89-102, 2012.

[4] D. Ma, J. Zhang, and H. Duan, "Reutilization of gangue wastes in underground backfilling mining: overburden aquifer protection," Chemosphere, vol. 264, no. 1, Article ID 128400, 2021.

[5] D. Ma, H. Duan, Q. Zhang et al., "A numerical gas fracturing model of coupled thermal, flowing and mechanical effects," Computers, Materials \& Continua, vol. 65, no. 3, pp. 21232141, 2020.

[6] D. Ma, H. Duan, J. Liu, X. Li, and Z. Zhou, "The role of gangue on the mitigation of mining-induced hazards and environmental pollution: an experimental investigation," Science of the Total Environment, vol. 664, pp. 436-448, 2019.

[7] D. Ma, H. Duan, X. Li, Z. Li, Z. Zhou, and T. Li, "Effects of seepage-induced erosion on nonlinear hydraulic properties of broken red sandstones," Tunnelling and Underground Space Technology, vol. 91, Article ID 102993, 2019.

[8] T. Liu, P. Yang, W. S. Lv, and K. Du, "Rock mechanical properties experiments with low-frequency circulation disturbance under different stress amplitudes," Journal of China Coal Society, vol. 42, no. 9, pp. 2280-2286, 2017.

[9] B. Sun, Z. Zhu, C. Shi, and Z. Luo, "Dynamic mechanical behavior and fatigue damage evolution of sandstone under cyclic loading," International Journal of Rock Mechanics and Mining Sciences, vol. 94, pp. 82-89, 2017.

[10] Y. Sun, Y. Yang, and M. Li, "Dynamic behavior and fatigue damage evolution of sandstone under uniaxial cyclic loading," Shock and Vibration, vol. 2020, Article ID 1452159, 9 pages, 2020.

[11] H. Xie, L. Li, R. Peng, and Y. Ju, "Energy analysis and criteria for structural failure of rocks," Journal of Rock Mechanics and Geotechnical Engineering, vol. 1, no. 1, pp. 11-20, 2009.

[12] Y. Li, D. Huang, and X. A. Li, "Strain rate dependency of coarse crystal marble under uniaxial compression: strength, deformation and strain energy," Rock Mechanics and Rock Engineering, vol. 47, no. 4, pp. 1153-1164, 2014.

[13] G. K. Zhang, H. B. Li, X. Xia, J. R. Li, C. Yu, and J. S. Liu, "Research on energy and damage evolution of rock under uniaxial compression," Rock and Soil Mechanics, vol. 36, no. S1, pp. 94-100, 2015.

[14] G. L. Wang, L. Zhang, M. Xu, Z. Y. Liang, and L. B. Ran, "Energy damage evolution mechanism of non-across jointed rock mass under uniaxial compression," Chinese Journal of Rock Mechanics and Engineering, vol. 41, no. 4, pp. 639-647, 2019.

[15] Z. X. Liu, W. Wang, J. Luo, and G. C. Miao, "Study on the method of energy evolution of rock under uniaxial compression test," Journal of China Coal Society, vol. 45, no. 9, pp. 3131-3139, 2020.

[16] Z. C. Wang, J. G. Zhao, S. C. Li, Y. G. Xue, Q. S. Zhang, and Y. Y. Jiang, "Fatigue mechanical behavior of granite subjected to cyclic load and its constitutive model," Chinese Journal of Rock Mechanics and Engineering, vol. 31, no. 9, pp. 1888-1900, 2012.

[17] F. Xiao, Z. Shen, G. Liu, Z. Zhang, and F. Zhang, "Relationship between hysteresis loop and elastoplastic strain energy during cyclic Loading and unloading," Chinese Journal of Rock Mechanics and Engineering, vol. 33, no. 9, pp. 1791-1797, 2014.

[18] Q. Meng, M. Zhang, L. Han, H. Pu, and T. Nie, "Effects of acoustic emission and energy evolution of rock specimens under the uniaxial cyclic loading and unloading compression," Rock Mechanics and Rock Engineering, vol. 49, no. 10, pp. 3873-3886, 2016.

[19] R. F. Du, X. J. Pei, X. C. Zhang, J. Jia, and J. Y. Chen, "Experimental study on energy response of argillaceous sandstone under cyclic loading," Journal of Engineering Geology, vol. 27, no. 3, pp. 505-515, 2019.

[20] Z. J. Zhang, J. B. Zhu, B. Wang et al., "The damage and shear dilation property evolution based on energy dissipation mechanism of gneissic granite," Rock Mechanics and Rock Engineering, vol. 37, no. S1, pp. 3441-3448, 2018.

[21] X. B. Yang, H. M. Cheng, J. Q. Lv, X. Hou, and C. G. Nie, "Research on energy consumption ratio evolution law of sandstones under triaxial cyclic loading," Rock and Soil Mechanics, vol. 40, no. 10, pp. 3751-3766, 2019.

[22] Y. Xu, C. J. Li, Q. Q. Zheng, X. Ni, and Q. Q. Wang, “Analysis of energy evolution and damage characteristics of mudstone under cyclic loading and unloading," Rock Mechanics and Rock Engineering, vol. 38, no. 10, pp. 2084-2091, 2019.

[23] International Society for Rock Mechanics (ISRM), "Suggested methods for determining the strength of rock materials in triaxial compression," International Journal of Rock Mechanics and Mining Sciences \& Geomechanics Abstracts, vol. 15, no. 2, pp. 47-51, 1978.

[24] X. R. Ge, Y. Jiang, Y. D. Lu, and J. X. Ren, "Testing study on fatigue deformation law of rock under cyclic loading," Rock Mechanics and Rock Engineering, vol. 22, no. 10, pp. 15811585, 2003.

[25] X. M. Li, C. Y. Liu, S. Speng, and Y. Lu, "Fatigue deformation characteristics and damage model of sandstone subjected to uniaxial step cyclic loading," Journal of China University of Mining \& Technology, vol. 46, no. 1, pp. 8-17, 2017. 